\section{Superficial Acral Fibromyxoma on the Second Toe}

So-Min Hwang, Ka-Hyung Cho, Kwang-Ryeol Lim, Yong-Hui Jung, Jennifer Kim Song

Aesthetic, Plastic and Reconstructive Surgery Center, Good Moonhwa Hospital, Busan, Korea

Correspondence: So-Min Hwang

Aesthetic, Plastic and Reconstructive Surgery Center, Good Moonhwa Hospital, 119 Beomil-ro, Dong-gu, Busan 601-803, Korea

Tel: +82-51-630-0199, Fax: +82-51-630-0145, E-mail: mdoc98@ hanmail.net

This study was presented at the 69th Congress of the Korean Society of Plastic and Reconstructive Surgeons on November 11-13, 2011 in Seoul, Korea.

No potential conflict of interest relevant to this article was reported.

Received: 1 Mar 2013 • Revised: 29 Apr 2013• Accepted: 25 May 2013 pISSN: 2234-6163 • elSSN: 2234-6171

http://dx.doi.org/10.5999/aps.2013.40.4.477 • Arch Plast Surg 2013;40:477-479 Copyright (C) 2013 The Korean Society of Plastic and Reconstructive Surgeons This is an Open Access article distributed under the terms of the Creative Commons Attribution Non-Commercial License (http://creativecommons.org/licenses/by-nc/3.0/) which permits unrestricted non-commercial use, distribution, and reproduction in any medium, provided the original work is properly cited.

Superficial acral fibromyxoma (SAF) was first reported by Fetsch et al. [1] in 2001; they described the distinctive soft tissue tumor, which had common clinical, histopathologic, and immunohistochemical features, in 37 patients [1-5]. To date, however, few cases of SAF have been described in the literature.

A 54-year-old man presented with a 1-year history of a slowly growing lesion on the volar surface of the left second toe and complained of tenderness when walking. On physical examination, the patient had a skin-colored quadrangular mass, measured as approximately $4 \mathrm{~cm} \times 4 \mathrm{~cm} \times 2 \mathrm{~cm}$ in size (Fig. 1A). It was a nodular lesion with a well-defined margin, but had no erosion, eschar, or bleeding. In addition, it did not invade the periungual or subungual region. Furthermore, it had a soft surface with soft tissue adhesion. There were no notable findings on radiography nor a family history. However, the patient did have a severalyear history of tinea pedis. The patient scratched the itching area, resulting in alternating wound healing and scarring. The patient was tentatively diagnosed with hypertrophic scar or keloid, for which we performed a complete resection of the mass (Fig. 1B). On histopathology, the mass was located underneath the hyperkeratinized epidermis, and it extended into the dermal and subcutaneous layer. Its cross-section showed a yellowish-white, jelly-like substance. Its histopathologic findings included a fascicular or storiform arrangement of spindle-shaped or stellateshaped tumor cells in the myxocollagenous matrix (Fig. 2A). These findings were suggestive of proliferative fibroblasts. Accentuated microvasculature was present in the matrix, accompanied by the overall presence of mast cells throughout the lesion. However, there was no marked presence of other inflammatory cells. Moreover, there was no dysplasia or hyperplasia of the tumor cells. On immunohistochemistry, the tumor cells were positive for CD34 and negative for desmin, S100, and epithelial membrane antigen (EMA) (Fig. 2B). The patient was eventually diagnosed with SAF. At a 12-month follow-up, there were no notable complications or recurrence (Fig. 3).

SAF is a solitary, nodular, slowly-growing, asymptomatic soft-tissue tumor with a well-defined margin. It is a rare tumor entity that mainly affects the soft tissue of the extremities and commonly occurs as a
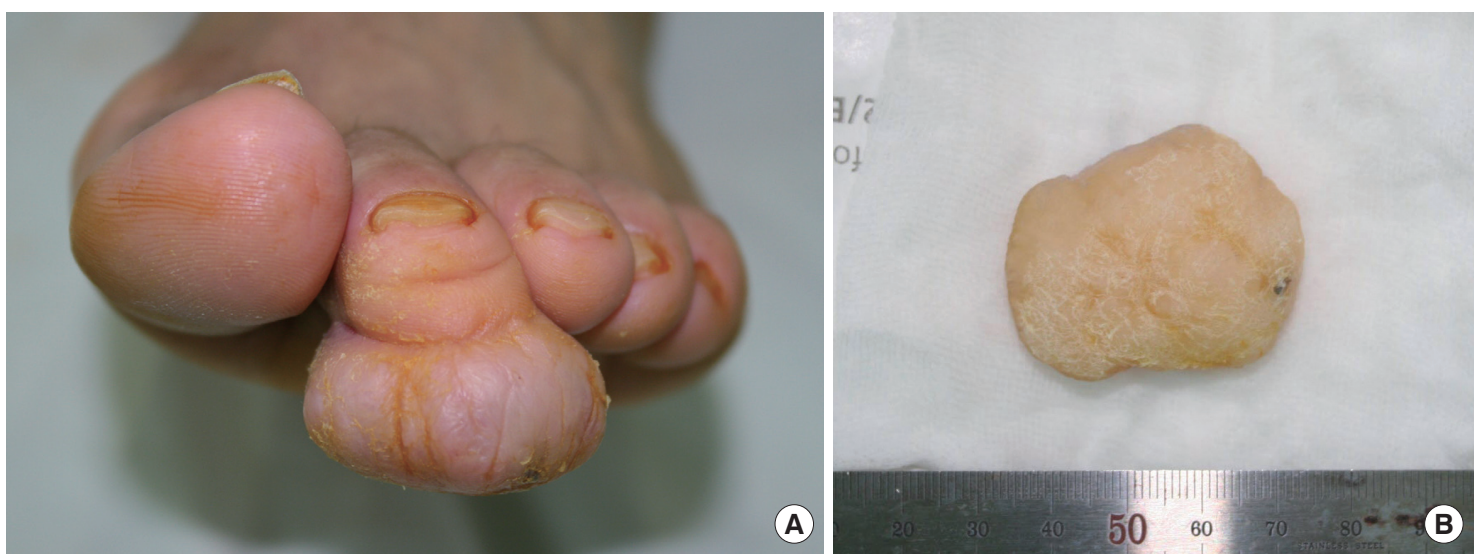

Fig. 1.

Preoperative and intraoperative clinical photos. (A) Preoperative clinical photo showing a $4 \mathrm{~cm} \times 4 \mathrm{~cm} \times 2 \mathrm{~cm}$ solitary skincolored mass on the volar side of the left second toe. (B) Resected specimen. 


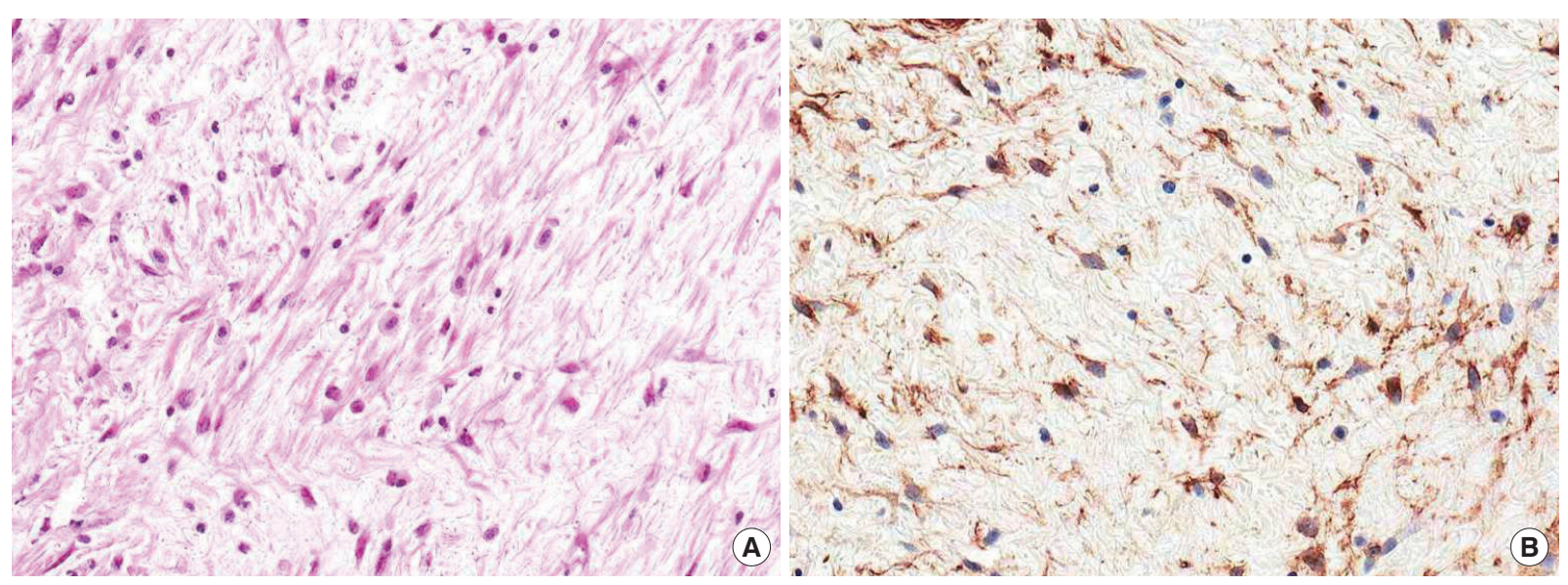

Fig. 2.

Findings of histopathologic and immunohistochemical stains. (A) Collection of spindle-shaped fibroblasts in a myxocollagenous matrix that blend into primarily myxoid areas of fibrous stroma $\left(H \& E_{1} \times 200\right)$. (B) Immunohistochemical stains ( $\left.\times 200\right)$ revealed that the sample was positive for CD34.

small nodule in the periungual or subungual regions of the fingers or toes. It has a predilection for middleaged adults, showing a male predilection with a maleto-female ratio of 2:1. In addition, the mean age of onset is estimated at 43 years. It can take 3 months to 30 years until a diagnosis of SAF is confirmed.

SAF is known to invade the nail, but causes no bone destruction on radiography. Grossly, the tumor has a semispherical polypoid or a verrucous shape. It also contains a grayish-white or yellowish-white jellylike substance on cross-sections [1-5].

Histopathologically, SAF is a non-encapsulated, well-circumscribed tumor. It commonly occurs in the

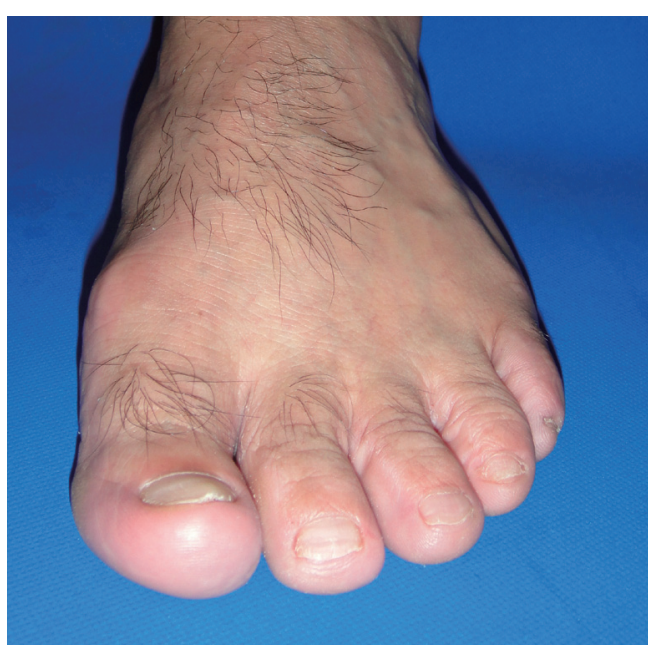

Fig. 3 .

Postoperative view. Good cosmetic results were achieved without recurrence (12 months later). dermis and sometimes extends into the subcutaneous layer. In the myxoid or myxocollagenous matrix, spindle-shaped or stellate-shaped fibroblast-like cells undergo a proliferation of moderate degree. There is an irregular, loose, fascicular or storiform arrangement of the tumor cells accompanied by the overall presence of mast cells. It has no other inflammatory cells $[1-5]$.

The myxoid matrix of the lesion is highlighted by alcian blue ( $\mathrm{pH} 2.5$ ) stain. On immunohistochemistry, it is positive for CD34, CD99, and vimentin but negative for S-100 protein, $\alpha$-smooth muscle actin, glial fibrillary acidic protein, keratin, and human melanoma black-45. There is variability in the immunoreactivity for CD10 and EMA [1-5].

Differential diagnoses of SAF include tumors with myxoid lesions (myxoid fibrous histiocytoma, superficial angiomyxoma, myxoid dermatofibrosarcoma protuberans, low-grade myxofibrosarcoma, and myxoid neurofibroma) and those mainly affecting the fingers and nails (sclerosing perineurioma, acquired digital fibrokeratoma, and periungual fibroma) [1-5].

Immunohistochemistry plays a particularly important role in the differential diagnosis of myxoid lesions with similar histopathologic features. Myxoid fibrous histiocytoma is negative for CD34 and positive for factor XIIIa. Superficial angiomyxoma is positive for CD34 and is negative for S100, which is similar to the immunohistochemical findings of SAF, but it is negative for both SMA and muscle specific actin. Myxoid dermatofibrosarcoma protuberans is positive for CD34 and vimentin, and is negative for EMA, desmin, 
and XIIIa. Low-grade myxofibrosarcoma is positive for vimentin, but it is negative for CD34 and desmin. Myxoid neurofibroma is a tumor of neural origin, showing positive immunohistochemistry for $\mathrm{S} 100$, which is of help in making a differential diagnosis of SAF [1-5].

It is known that SAF has a benign natural course, for which the standard treatment modality is complete surgical removal. Incomplete surgical removal might cause a recurrence. Patients with SAF should be under regular follow-up. Prescott et al. reported that SAF had nuclear pleomorphism or mitotic activity showing malignant potential, but its malignant transformation or metastasis has not been described [1-5].

\section{References}

1. Fetsch JF, Laskin WB, Miettinen M. Superficial acral fibromyxoma: a clinicopathologic and immunohistochemical analysis of 37 cases of a distinctive soft tissue tumor with a predilection for the fingers and toes. Hum Pathol 2001;32:704-14.

2. Ashby-Richardson H, Rogers GS, Stadecker MJ.

Superficial acral fibromyxoma: an overview. Arch Pathol Lab Med 2011;135:1064-6.

3. Hollmann TJ, Bovee JV, Fletcher CD. Digital fibromyxoma (superficial acral fibromyxoma): a detailed characterization of 124 cases. Am J Surg Pathol 2012;36:789-98.

4. Goo J, Jung YJ, Kim JH, et al. A case of recurrent superficial acral fibromyxoma. Ann Dermatol 2010;22: 110-3.

5. Choi JH, Lee HJ, Jung SY, et al. A case of superficial acral fibromyxoma occurring after trauma in a childhood patient. Korean J Dermatol 2010;48:123-6.

\section{Multiple Sparganosis in an Immunosuppressed Patient}

Hong Sang Yoon ${ }^{1}$, Byung Joon Jeon ${ }^{2}$, Bo Young Park ${ }^{1}$

${ }^{1}$ Department of Plastic Surgery, Samsung Medical Center, Sungkyunkwan University School of Medicine, Seoul; ${ }^{2}$ Department of Plastic and Reconstructive Surgery, Ansan Hospital, Korea University College of Medicine, Ansan, Korea

Correspondence: Bo Young Park

Department of Plastic Surgery, Samsung Medical Center,

Sungkyunkwan University School of Medicine, 81 Irwon-ro, Gangnam-gu, Seoul 135-710, Korea

Tel: +82-2-3410-2235, Fax: 82-2-3410-0036

E-mail: byps.park@samsung.com

No potential conflict of interest relevant to this article was reported.

Received: 14 Mar 2013 • Revised: 23 Apr 2013 • Accepted: 26 Apr 2013 pISSN: 2234-6163 • elSSN: 2234-6171

http://dx.doi.org/10.5999/aps.2013.40.4.479 • Arch Plast Surg 2013;40:479-481

Copyright (C) 2013 The Korean Society of Plastic and Reconstructive Surgeons

This is an Open Access article distributed under the terms of the Creative Commons

Attribution Non-Commercial License (http://creativecommons.org/licenses/by-nc/3.o/)

which permits unrestricted non-commercial use, distribution, and reproduction in any medium, provided the original work is properly cited.

Most of the parasitic infections that occur in Far East Asia including China, Japan, and Korea result from ingestion of infected water or the raw flesh of snakes or frogs.

The most common clinical manifestation of sparganosis is a subcutaneous mass or lump in the breast, abdominal wall, scrotum, lower extremity, or chest wall. The larvae can invade tissues including muscle, intestine, eye, brain, and spinal cord and can also cause pericardial effusion. The mass may be mistaken for a malignant tumor, thereby causing difficulty in terms of diagnosis and treatment. In this article, we report an interesting case of sparganosis that presented as two separate subcutaneous masses involving the axillary and inguinal area in an immunosuppressed patient 45 years after the initial ingestion of contaminated food. A 61-year-old man visited our clinic with two $3 \mathrm{~cm}$ painless, movable, hard masses

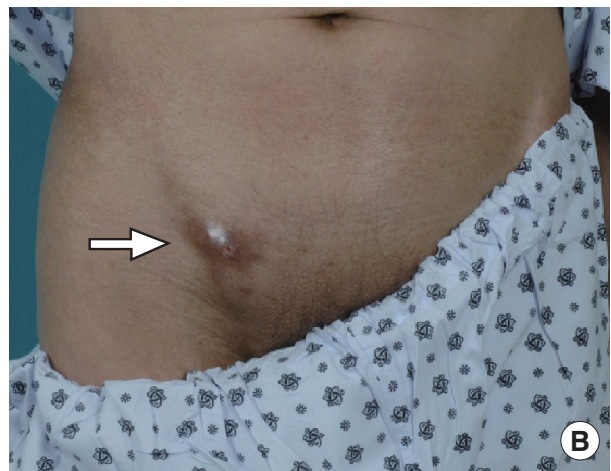

Fig. 1

Preoperative (A) right axillary, (B) inguinal masses (white arrow). 